\title{
La confianza como retórica, el estatus como práctica: comerciantes estadunidenses y relaciones de agencia en el Caribe español (1798-1822)
}

\author{
Trust as Rhetoric, Status as Practice: \\ American Merchants and their \\ Agency Relations in the Spanish Caribbean \\ (1798-1822) \\ Jesús Bohorquez \\ European University Institute, Fiesole, Italia, email: Jesus.Bohorquez@eui.eu
}

\begin{abstract}
Resumen. El objetivo principal de este artículo es analizar los problemas fundamentales del comercio a larga distancia: selección de agentes y mantenimiento de relaciones. Se estudian las relaciones comerciales que envolvían los comerciantes estadunidenses localizados en Boston, Providence, Bristol, Filadelfia y sus agentes en el Caribe español, en específico, La Habana. Los resultados ofrecidos están basados en la lectura de aproximadamente 15000 cartas conservadas en los archivos de Estados Unidos. El artículo busca complementar, desde una perspectiva microeconómica, los datos macroeconómicos que se disponen sobre las relaciones cubano-estadunidenses. Se concluye que el estatus -y no la confianza- fue central en la construcción de relaciones de larga distancia, y que los comerciantes estadunidenses desempeñaron un papel fundamental conectando los mercados del Caribe y de Asia.
\end{abstract}

Palabras clave: historia atlántica; comerciantes estadunidenses; comercio Caribe-Estados Unidos; instituciones mercantiles; organización institucional.

Abstract. This paper's main goal is to analyze the fundamental problems of exchange, it is, long-distance agency relations. It discloses commercial relations involving American merchants based in Boston, Providence, Bristol, and Philadelphia and their agents based in the Spanish Caribbean, mainly Havana. It draws on a vast mercantile correspondence available in American archives, which has largely been ignored by historians working on the Spanish Empire. The paper's main outcomes are backed on the reading of approximately 15000 letters. It elucidates on issues related to mercantile organization. Here a microeconomic approach has been chosen to examine the way in which the trade was organized. The paper concludes highlighting the role statues and not trust played in building long-distance agency relations as well as offering information and on the role American merchants played in connecting Caribbean and Asian markets. 
Key words: Atlantic history; North American traders; Caribbean-US trade; mercantile institutions; institutional organization.

JEL: N8; N80; N81; N86.

Fecha de recepción: 4 de enero de 2017. Fecha de aceptación: 31 de marzo de 2017.

\section{INTRODUCCIÓN}

$\mathrm{E}$ 1 mercado de la isla de Cuba se constituyó sin lugar a dudas en uno de los más dinámicos del imperio español durante el tránsito del siglo XVIII al XIX. Las razones atribuidas para explicar tal crecimiento son múltiples: las ganancias generadas por el auge azucarero, principalmente después de la caída de Santo Domingo en 1792; importantes entradas de moneda desde México; una poderosa y bien conectada elite local, entre otras. ${ }^{1}$ Grandes cantidades de plata disponible atraían no sólo a comerciantes de la península, sino también a los extranjeros. No hay duda de que uno de los mayores puertos del Caribe se convirtió en un imán que generó gran interés en las casas comerciales de diferentes puertos de Estados Unidos. No obstante, pocos trabajos existen sobre las relaciones de estos agentes y su impacto en el mercado habanero.

La mayor parte de los estudios sobre el mercado de La Habana se han concentrado ya sea en aspectos macroeconómicos o en las políticas de la corona. En lo que respecta al primer aspecto, sin lugar a dudas, las tendencias del mercado habanero han sido analizadas usando como recurso las balanzas de comercio y una gran cantidad de información recolectada por el consulado de comerciantes de la ciudad (Amores, 2000; Fernández, 2000, 2002; Sagra, 1831). En lo que respecta al segundo aspecto, es recurrente encontrar en la historiografía tópicos tales como el impacto de las reformas borbónicas en el comercio; o bien, el comercio neutral el cual impuso una alta inestabilidad comercial debida a la continua apertura y cierre de puertos entre 1797 y 1810. A pesar de que este último fenómeno ha llamado ampliamente la atención, hasta ahora se cuenta con las innumerables peticiones del Consulado, más bien con poco suceso, para intentar abrir una y otra vez el puerto. El impacto negativo de tales políticas españolas en el crecimiento de la isla (o crecimiento a pesar del marco institucional prevalente) no ha sido todavía evaluado. Otro tópico muy

${ }^{1}$ Moreno (1964), Tornero (1996), Knight (1977), González-Ripoll (1999), Piqueras (2008), Vázquez (2008), Gonçalves (2008), Kuethe e Inglis (1985). Sobre las grandes importaciones y salidas de plata, véanse Irigoin (2009) y Marichal y Souto (1994). 
estudiado es el contrabando, un problema sobre el que es difícil establecer tendencias pero que en algunas ocasiones puede ser sobreestimado. Contrabando y comercio neutral, así como su cuantificación, han sido relacionados con la participación de los comerciantes estadunidenses e ingleses. ${ }^{2}$ Por otra parte, el debate sobre comercio neutral ha estado basado en el análisis de documentos oficiales, y en concreto, en las disputas entre diferentes puertos (Cádiz y Veracruz contra La Habana).

No se cuenta aún con una aproximación microeconómica que dé cuenta de problemas relacionados con la selección de los agentes y la toma de decisiones por parte de tales agentes en diferentes condiciones (decisiones que, por otra parte, no respondían sólo a la apertura y cierre de puertos o a las tan recurrentes narrativas sobre negocios encubiertos). Uno de los problemas para llevar a cabo un estudio microeconómico que complemente los aspectos macroeconómicos ya estudiados es la ausencia de una documentación detallada que permita examinar en particular las diferentes casas comerciales y la manera como actuaron en el mercado habanero. Contrario a lo que sucede en el caso del imperio español donde es difícil encontrar este tipo de documentos, o donde se encuentran algunos rastros en secciones judiciales en razón de quiebras o demandas, una gran documentación se encuentra disponible y bien conservada en los archivos de Estados Unidos. Se trata de archivos particulares completos, con la correspondencia por décadas, libros de cuentas, facturas, libros de los barcos, etc. A pesar de que estos documentos se encuentran en un estado de catalogación sorprendente hasta ahora no han sido explorados por los historiadores que se ocupan de trabajar el imperio español. ${ }^{3}$ Es con esta documentación que este artículo busca ofrecer una aproximación microeconómica. Una visita por los diferentes archivos locales de la costa Este, desde Nueva Inglaterra hasta Pensilvania ha permitido realizar una lectura de más de 15000 cartas que no se limitan a las relaciones Estados Unidos-Cuba sino también a la de los comerciantes estadunidenses con Europa, por ejemplo, para rastrear las ganancias causadas por el transporte de azúcar cubano, o Asia, pues como se verá los estadunidenses se convirtieron en importantes intermediarios entre los puertos del Índico y los del Caribe.

$\mathrm{El}$ artículo tiene dos objetivos. Por una parte, enriquecer desde una perspectiva microeconómica los análisis con los que hasta ahora se cuenta sobre las relaciones Cuba-Estados Unidos (Barbier y Kuethe, 1984; Sal-

${ }^{2}$ Para una discusión al respecto, véanse Pearce (2007) y Cuenca-Esteban (2014).

${ }^{3}$ Linda Salvucci $(1985,1991,2005)$ ha estudiado las relaciones cubano-estadunidenses y ha analizado los archivos localizados en Filadelfia. Los historiadores latinoamericanos han mostrado poco interés en explotar la abundante información comercial localizada en esos archivos. 
vucci, 1985, 1991, 2005). Por la otra, aportar en el conocimiento de los comerciantes que actuaron en el puerto de La Habana, sobre los que existe un desconocimiento absoluto, pues es bien sabido que, mientras los dueños de ingenios han llamado la atención, nada se sabe sobre el importante grupo de comerciantes de uno de lo más importantes puertos Atlánticos. ${ }^{4}$

\section{DE LAS REDES SOCIALES A LAS INSTITUCIONES MERCANTILES}

¿Cuáles eran los problemas fundamentales que afrontaba un comerciante ubicado en un puerto de Estados Unidos (ya fuese este Filadelfia, Boston, Providence o Bristol) para enviar su cargamento sin tener que desplazarse a un puerto extranjero como La Habana? En primer lugar, se debía contar con un agente en la isla o de lo contrario enviar un agente a quien pudiese confiar la toma de decisiones a larga distancia. Es importante resaltar que en el caso español, los negociantes extranjeros estaban obligados a entregar sus mercancías a un comisionista nacional. En segundo lugar, necesitaba tener acceso a una información certera que le permitiera saber con exactitud las demandas del mercado de destino. En tercer lugar, estar seguro de recibir las ganancias producidas por las mercancías vendidas (y, sobre todo, estar seguro de que las recibiría en el tiempo adecuado) siguiendo de cerca las necesidades del mercado en el que se hallaba localizado. Por ejemplo, un aumento del precio del azúcar en Hamburgo requería una mayor demanda del producto en los puertos estadunidenses para reexportación. Por el contrario, la llegada masiva del producto podía bajar demasiado sus precios ocasionando pérdidas. La próxima partida de un barco hacia Calcuta, Macao u otros puertos en el Índico demandaba cantidades significativas de plata. La toma de decisiones de agentes ubicados en Baltimore, dedicados a las remesas de harina, no sería la misma que la de una casa comercial ubicada en Boston o Bristol. En resumen, era necesario hacer una selección de agentes confiables.

Durante los últimos años, una amplia literatura multidisciplinaria se ha ocupado de buscar una respuesta satisfactoria a dicho dilema. Es posible establecer, por lo menos, dos tendencias. Por una parte, existen modelos basados en teoría microeconómica y teoría de juegos que proponen un modelo autoorganizativo donde la configuración de coaliciones de comerciantes y una amplia circulación de información hacía posible el mantenimiento de amplios niveles de confianza basados en la buena reputación de los agentes participantes. Uno de los autores que ha desarrollado más esta perspectiva es Avner Greif $(2000,2006,2012)$. Su modelo es el de la

\footnotetext{
${ }^{4}$ Véanse, por ejemplo, Böttcher (2011), Lewis (1984) y Debien (1953).
} 
maximización de la utilidad y no el de la ayuda mutua o del favor desinteresado. Puesto que un agente estaba interesado en mantenerse empleado por varios agentes a través de la institución llamada comenda, y puesto que a su vez su futuro empleo dependía exclusivamente de un comportamiento honesto (pasado objetivado en reputación), entonces, se obtenían mayores beneficios de un comportamiento creíble que de una actuación deshonesta en una sola oportunidad, la que automáticamente tenía como consecuencia el ser vetada por los demás miembros del grupo. $\mathrm{Al}$ poner en circulación rumores sobre el comportamiento deshonesto de un individuo, los demás miembros de la comunidad tenderían a no usar sus servicios. Existen, por otro lado, modelos basados en teoría sociológica y antropológica, los cuales colocan el acento en el papel de la cultura, las relaciones cercanas, el capital social, la creación de lazos íntimos, o en el respaldo de las transacciones en un tipo preciso de lazos culturales. A este respecto es bien conocido el modelo de Granovetter (1978) sobre la creación de lazos estrechos. ${ }^{5}$

Por un lado, aparecen conceptos como confianza y reputación, que no deben ser confundidos, mientras que, por el otro, una particular atención es prestada al concepto de capital social, el cual cabe decir ha sido ampliamente criticado por su imprecisión conceptual. ${ }^{6}$ La reflexión teórica ha sido acompañada por trabajos basados en una amplia documentación y en un análisis riguroso de la misma. Por ejemplo, una forma de rastrear y medir la reputación de un agente que participa en un grupo específico es medir en la correspondencia mercantil la circulación de referencias hechas sobre los involucrados. Goldberg (2012, pp. 78-79), por ejemplo, ha demostrado, a través de un riguroso análisis cuantitativo de contenido de las cartas de comerciantes también utilizadas por Greif, que el total de espacio dedicado a hablar sobre el comportamiento de los agentes en relación con su reputación (honestidad) es insignificante. Por tanto, una evaluación cuantitativa del contenido de las cartas no parece respaldar la idea de que estas estuviesen destinadas a crear una red de circulación de información en torno a la reputación de los otros.

De la misma manera, en el modelo de carácter más microeconómico la reputación permite seleccionar maximizando la utilidad entre un con-

\footnotetext{
${ }^{5}$ Un buen ejemplo de la relación entre vínculos grupales generados por pertenencia geográfica común y comercio ha sido analizado en el caso del imperio español con el ejemplo de los vascos, vasco-navarros, catalanes, montañeses, etc. Sobre redes de comerciantes de estos grupos y los conflictos por ellas generados existe una amplia historiografía: Socolow (1978), Valle (2012), Böttcher, Hausberger e Ibarra (2011), Stein y Stein (2009) y Lamikiz (2010, 2011).

${ }^{6}$ Trivellato (2009, pp. 10-16), Haggerty (2012, pp. 66-96), Lamikiz (2010, pp. 9-14), Vanneste (2012, pp. 29-33), Zahedieh (2010, pp. 106-113). Para el debate conceptual sobre confianza y reputación, véanse Williamson (1993), Guinnane (2005) y Gambetta (1988).
} 
junto determinado de socios, mientras en el modelo que emplea el capital social y las relaciones culturales los vínculos compartidos de alguna manera contribuyen en la generación de confianza y con ello al mantenimiento de vínculos comerciales. Hay cierta idea subyacente en ambos modelos de acuerdo con la cual un agente recurriría al mismo agente siempre y para todo tipo de operaciones. La selección de los agentes parece ser mucho más azarosa de lo que se piensa. Si se toma la ciudad de Génova en una larga temporalidad de varios siglos, las transacciones comerciales muestran que la gran mayoría de los comerciantes genoveses involucrados en comercio de larga distancia eran más bien participantes ocasionales. Muy pocos tendían a seleccionar al mismo socio en repetidas ocasiones. Por ello, la reincidencia de las operaciones parece no haber sido la norma sino la excepción dando más bien lugar a un comportamiento oportunista en la selección de los agentes (Doosselaere, 2006, pp. 102-103).

Este artículo busca precisamente prestar atención al proceso de selección y mantenimiento de contacto con determinados agentes, y hasta qué punto ella era más oportunista de lo que hasta ahora se ha propuesto. Para ello, además, se introducirá en el debate un fenómeno poco estudiado para el caso español. Se analiza el giro del capital a través de las instituciones mercantiles que los agentes seleccionaban para remitir su capital a larga distancia y recibir ganancias de acuerdo con sus órdenes. ${ }^{7}$ Resulta fundamental prestar atención a cada una de las instituciones empleadas y sus diferencias pues son estas las que explican quién era el propietario del capital, quién realiza la operación, y quién corría el riesgo pagando a cambio una comisión. A diferencia de lo que sucede con los trabajos de redes, sobre los cuales existe una amplia literatura, este enfoque ha sido raramente empleado por la historiografía, lo que ha llevado, entre otras cosas, a una recurrente confusión sobre propiedad y riesgo de capital.

\section{SELECCIONAR LOS AGENTES (OPORTUNISTAMENTE)}

Los comerciantes deseosos de despachar mercancías hacia diferentes puertos de destino contaban con diferentes opciones para tener seguridad sobre el posible buen resultado de sus negociaciones. La decisión dependía en cierta medida del mercado de destino. Por ejemplo, para los barcos destinados hacia los mercados africanos, los cuales eran percibidos como ampliamente impredecibles, negociantes americanos y británicos entregaban a los capitanes de barco órdenes que dejaban un gran margen de

\footnotetext{
${ }^{7}$ Sobre instituciones mercantiles y las operaciones de giro, véanse Lopez e Irving (1967), Price (1989), Nash (2005), Hancock (1995), Trivellato (2009), Gelderblom (2013) y Strum (2014).
} 
actuación y de toma de decisiones a estos (Haggertty, 2009). Otra opción era recurrir a un agente conocido como sobrecargo, quien no era otro que un representante encargado ya fuese de seleccionar el consignatario, ya de ejecutar él mismo las órdenes recibidas o de actuar de la manera más conveniente según su interpretación de las variables del mercado donde llegaba. Es difícil responder exactamente cuáles eran los costos de transacción de enviar un sobrecargo o de emplear un agente consignatario. Eran estos sobrecargos o los capitanes los que en buena parte de los casos se ocupaban de seleccionar los agentes en La Habana. El papel de intermediario era entonces esencial, tanto para los negociantes americanos, como de aquellos ubicados en la isla quienes buscaban que se les consignase la mayor cantidad de cargamentos disponibles en el muelle del puerto.

En el proceso de selección varios factores parecen intervenir. Para comunidades mercantiles cuya reproducción estaba basada primordialmente en la incorporación de agentes provenientes de capas rurales pobres que buscaban integrarse al mercado de trabajo disponible en el mundo del comercio, y que a su entrada a menudo no contaban con ningún capital (fuese este material, simbólico o social), se escogían agentes con vínculos de pertenencia geográfica común. Sin duda alguna, comerciantes ubicados en América frecuentemente solicitaban que sus hijos, sobrinos u otros familiares y amigos se trasladasen desde la península. Así, es difícil evaluar hasta dónde se trataba de vínculos de confianza, o bien, de una ausencia de capital que obligaba a unos a recurrir a conocidos y a otros a depender de conocidos (saliendo de las montañas del norte de la península era difícil estar en contacto con una amplia red que no fuese la familia, o los conocidos del valle) para ingresar en un mundo que no siempre era muy receptivo al ingreso de outsiders, y por tanto, de mayor competición. ${ }^{8}$ No es sorprendente entonces que empezasen como sirvientes o bajo el dominio del padre, tío, etc., así como no es sorprendente que se les catalogue en ese primer momento como bichos (Bohorquez, 2016, pp. 300-388).

En el establecimiento de vínculos con los estadunidenses queda evidenciado, por una parte, el dinamismo de la configuración y disolución de las sociedades comerciales así como la evolución y transformación de las redes. Un dinamismo y evolución temporal de una velocidad tal que la reconstrucción de redes sincrónicas difícilmente puede dar cuenta. Si du-

\footnotetext{
${ }^{8}$ Aunque el uso de familiares y paisanos puede ser interpretado como relaciones de confianza, y por tanto, de alto capital social, existen estudios que demuestran y miden lo contrario, es decir, que agentes viviendo en zonas con bajos niveles de capital social tienden a cooperar menos y a confiar menos en personas sin vínculos de parentesco (Amore, 2016). En otras palabras, y como hipótesis, que la endogamia resultase eficiente bajo patrones de oligopolio, como los ofrecidos por el sistema imperial español, aunque no se sabe sobre su eficacia en contextos de competencia abierta.
} 
rante el traslado a Cuba la mayoría dependía de sus familiares y se arrojaba al mar huyendo de la pobreza sólo con la ropa puesta, la situación era diferente una vez acumulado algún capital. Esto les permitía moverse en el mercado relacionar sin depender en gran medida de vínculos que se catalogan como de identidad. En 1800, Francisco Hernández disolvía su sociedad comercial con Simón Poey para establecer otra con un comerciante de origen francés llamado Juan José Chauviteau. Muy probablemente era este último quien tenía los contactos en Nueva Inglaterra, entre los cuales estaba Samuel Arnold en Providence y los D'Wolf en Bristol (Rhode Island). ${ }^{9}$ Además, en La Habana haría parte de la sociedad otro comerciante estadunidense llamado John Line, quien ya había trabajado con Chauviteau..$^{10}$ De acuerdo con cierta información judicial, en el momento de su fallecimiento en Cádiz en julio de 1803, Poey tenía una casa comercial que giraba bajo el nombre Poey y Cía., cuyos socios eran su hermano Juan Andrés Poey y Juan Francisco Sanguilí. En 1804 las dos casas comenzaron a correr bajo el nombre de Viuda de Poey y Hernández (Jurisprudencia Civil, 1861, p. 322). A finales del siglo XVIII Sebastián Lasa se asociaba como Santa María y Cuesta y Pierre Thomas Denis (originario de Nantes), mientras en 1807 aparece asociado con Juan José Iriarte. ${ }^{11}$

Un francés, Thomas Gimbal, natural de Auch se embarcó en negocios con agentes procedentes de diferentes orígenes. Según se deja ver en su testamento, Gimbal había comprado catorce caballerías de tierra donde se habían establecido por lo menos dos cafetales diferentes, uno de ellos El Recurso, en compañía de Juan Murdock y José Seul, quienes fueron decla-

${ }^{9}$ El clan D’Wolf tuvo una alta participación en el tráfico de esclavos, tanto antes como después de la revolución americana. Participaron e invirtieron capital en 88 viajes en promedio, siendo una de las fortunas de Rhode Island que se encontraba verdaderamente cimentada en el comercio de ron y esclavos. Se convirtieron en factores en los mercados de esclavos de La Habana y Charleston (Coughtry, 1981, pp. 48-49). Aunque no he podido localizar el expediente de naturalización de Chauviteau, se cuenta con alguna información debido al secuestro de los bienes que se hicieron a los franceses en 1809, a pesar de que ya había obtenido carta de naturalización. Nacido en la isla de Guadalupe, su familia había emigrado hacia Estados Unidos cuando aún era muy joven. Se integró en la milicia inglesa para enfrentar a Francia y después en 1796 pasó a instalarse en La Habana trabajando en la casa de comercio de Francisco Hernández, quien después se convertiría en su socio. En el puerto se había casado con Serafina Moy, una habanera con la que tenía cuatro hijos. En 1809, cuando se ordenó el secuestro de los franceses residentes en la isla, al parecer Chauviteau había viajado para Estados Unidos, dejando a Hernández encargado de sus negocios. Entre los bienes que este mencionó estaba la participación (un cuarto o mitad) en por lo menos cuatro cafetales, dos de ellos en compañía con el mismo Hernández y el otro con el comerciante estadunidense de Bristol, D'Wolf. Al dejar La Habana, Chauviteau había dejado letras a favor de diferentes miembros de la familia de comerciantes de Bristol por un valor de 101250 pesos que debían ser girados con la cosecha de sus cafetales. Archivo General de Indias (en adelante AGI), Ultramar, 166.

${ }^{10}$ John Carter Brown Library (JCB), Arnold Paper, caja 25.

${ }^{11}$ Philosophical Historical Society (en adelante PHS), Girard Papers, 4 de abril de 1800 y 16 de febrero de 1807. 
rados sus herederos. ${ }^{12}$ En 1812, cuando solicitó la nacionalidad española, José Seul llevaba viviendo en la isla por lo menos doce años, habiéndose instalado allí en 1798. Procedente de la ciudad de Filadelfia, Seul era hijo de irlandeses católicos y había llegado a La Habana con cartas de recomendación firmadas por el cónsul español. Había comenzado a trabajar en la casa de Leonardo Vinarte, y tras su muerte en 1802, lo hizo con Gimbal. En 1811, debido a la muerte de este, entró a trabajar a los servicios de Santiago Drake al igual que Murdock. ${ }^{13}$ Este último había llegado desde Filadelfia a La Habana en 1798 con varias cartas de recomendación de sujetos respetables dirigidas a Tomás Gimbal. Santiago Drake, por su parte, había nacido en Londres, donde había aprendido las primeras letras y se había entrenado en el oficio del comercio. De allí había pasado a Jamaica con varias negociaciones, trasladándose luego hacia Cartagena en 1788 y finalmente a la península en 1791, solicitando la nacionalidad española que le fue concedida para los reinos de la península. En 1792, Drake aparece de nuevo en Cartagena demandando la extensión de la nacionalidad para poder permanecer en las Indias ${ }^{14}$ (Gonçalves, 2008, p. 345). La casa comercial de Drake fue muy utilizada por comerciantes de Boston.

No hay duda de que la entrada de los estadunidenses en el mercado habanero brindó un cierto dinamismo a la estructuración y reestructuración de las sociedades. Es posible encontrar por lo menos dos situaciones relacionadas con la selección de agentes: el sobrecargo selecciona según su parecer el consignatario, o ancla en el puerto de destino con órdenes precisas de entregar el cargamento a un consignatario previamente seleccionado por el patrón. En ambos casos era posible entregar la carga ya fuese a un estadunidense -o a uno que estuviese asociado con un español- o a un español. No es raro que los sobrecargos se decidan por nombrar como consignatario a un compatriota, sobre todo durante los primeros viajes, una vez que este probaba ser eficiente en el manejo del cargamento podía solicitar o no las siguientes remesas. Ahora bien, para ello debía contar con la doble aprobación del patrón en Estados Unidos y también con una recomendación hecha por el capitán. Esta última sin lugar a dudas debía corresponder con una serie de favores que se hacían para ganarse primero la entrega del cargamento y luego la recomendación del capitán, aunque en las cartas se tiende a utilizar la retórica de la confianza: "espero que el manejo dado a esta operación se convierta en el fundamento de una correspondencia recíproca y mutua". No se debe olvidar que la selección de un agente tenía repercusiones en las competencias del capitán o sobre-

\footnotetext{
${ }^{12}$ AGI, Ultramar, 166.

${ }^{13}$ AGI, Ultramar, 166.

${ }^{14}$ AGI, Santa Fe, 1016.
} 
cargo, sobre todo cuando aquel no tenía acciones invertidas en los barcos y por tanto contaba con poco margen de negociación ante el patrón.

Escoger un agente y reenviar cargamentos en varias ocasiones no implicaba que se utilizaba el mismo agente siempre y para todo. Por ello, se expone en las cartas que se "confiaba" de nuevo cargamento, una decisión tomada "a pesar de que el negocio era altamente solicitado por otros", una advertencia, sin duda, encubierta en la retórica de la confianza. Una alternativa para testar la potencialidad de varios agentes era repartir el cargamento entre potenciales candidatos, o solicitar el cobro de deudas (lo que implicaba mantener una cuenta) a varios agentes. Esto permitía no sólo disminuir el riesgo en pequeñas cantidades, sino también testar cuál se tornaba más eficiente o interesado en cumplir con presteza el encargo. ${ }^{15}$

Los consignatarios estaban sometidos a una alta presión por la alta demanda que había por consignaciones, y tal demanda los obligaba a aumentar su eficiencia para ser empleados de modo recurrente. Una enorme cantidad de cartas circulaba no precisamente con información sobre la reputación de los terceros, sino con algo que se denominaba el estado del mercado y que será analizado en la tercera sección de este artículo. Esta información, enviada a menudo con cartas de invitación o con cartas de recomendación, proveía datos importantes sobre el comportamiento del mercado e indirectamente permitía evaluar como positivo o negativo el desempeño de agentes determinados. Si se analiza sincrónicamente la correspondencia de la casa comercial Bryan-Sturgis para enero de 1816 (véase figura 1), se puede apreciar que los negociantes en Nueva Inglaterra recibían simultáneamente toda una serie de informaciones de capitanes, comerciantes, sobrecargos, entre otros, que de alguna manera daba cuenta del comportamiento del mercado y dejaba poco margen de acción a los agentes, es decir, poca probabilidad de enviar información falsa sobre el mercado, omitir encuentros, mentir sobre precios, etc. Se trata de una supervisión indirecta que muestra hasta dónde la confianza tan utilizada y mencionada en las cartas era más bien una retórica, o se resaltaba para evitar mencionar los cálculos que la anticipaba o le daba sentido.

El sobrecargo, sin embargo, podía llegar con indicaciones precisas de a quién debía entregar el cargamento. Aquí era el patrón quien tomaba la decisión tomando en consideración diferentes cálculos. Es importante señalar que una de las ideas de tener consignatarios no era sólo la de vender el cargamento, sino también contar con cuentas (a dos columnas) en diferentes ciudades, lo que aumentaba la capacidad de mover capitales entre diferentes espacios. Estos arreglos de cuentas podían desempeñar un papel determinante en la selección de los agentes. Por medio de un consignatario

\footnotetext{
${ }^{15}$ PHS, Girard Papers, 23 de septiembre de 1800.
} 


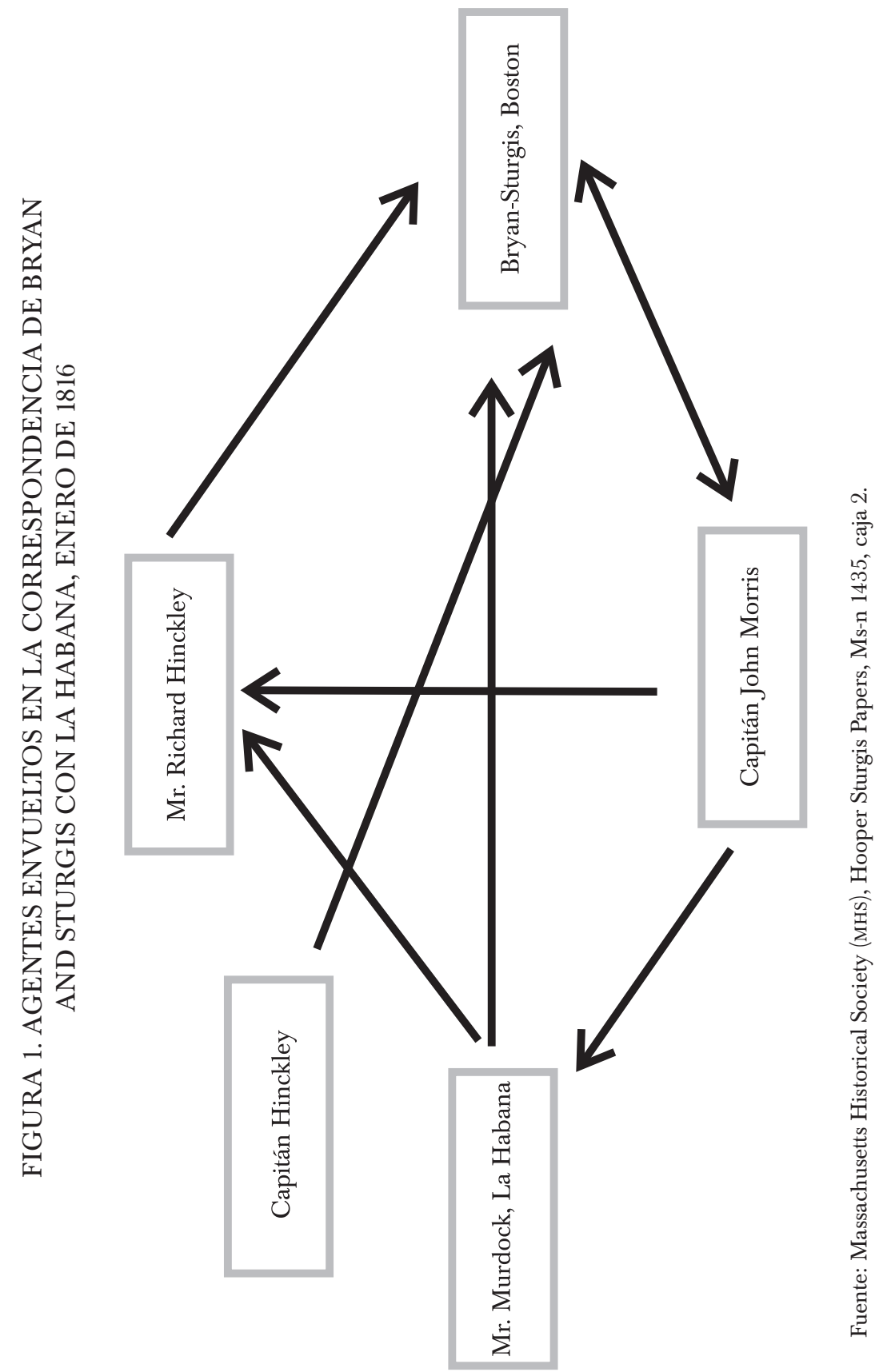


en La Habana se podían cerrar o abrir negocios con otro en Charleston sin necesidad de emitir letras (y pagar intereses) o de mover moneda pagando fletes y arriesgándola a los peligros del mar. Además, por medio de un agente menos interesante se podía llegar a otro más interesante. La cantidad de contactos resultaba relevante, pero también lo era la calidad de los mismos. Esto es claro en las cartas de recomendación, cuando se solicitaban cargamentos consignados. Los remitentes informaban a su potencial patrón no sólo quién los recomendaba, sino además sus contactos en diferentes ciudades. Importaba menos la carta de recomendación que la persona que la firmaba.

El estatus del agente, un fenómeno hasta ahora pasado por alto, resultaba de vital importancia. Se ha llamado la atención sobre la reputación y la confianza, mientras que el estatus se ha dejado de lado. A diferencia de la reputación (esto es el comportamiento pasado del agente, que puede brindar cierta probabilidad sobre su comportamiento futuro), el estatus reenvía a una posición de jerarquías que genera un impacto mayor en las respuestas de los agentes. El estatus, contrario de lo que sucede con la reputación (la cual cada agente debe ganar o perder) es un capital simbólico transferible (la mayor parte de los agentes reconocerá el estatus de una determinada casa comercial en relación con otras). La eficiencia del trabajo de un consignatario era conocida por su patrón, pero no era algo que necesariamente se comunicaba a todo el grupo a través de la correspondencia (excepto que un tercero recomendase a alguien). Por ello, en parte, para los agentes resulta difícil seleccionar a alguien tomando como criterio de selección su reputación. Además, puede ser que existiesen varios agentes en el mercado de consignatarios con el mismo grado de reputación. El estatus está por tanto relacionado con el capital simbólico que una casa comercial disponía. Este reenvía a la jerarquía de las diferentes casas comerciales, jerarquía que se alcanza por la disponibilidad de un agente para realizar favores a amigos y terceros o de ser neto beneficiario de favores por causa de su estatus, y que se relaciona con su capital material y la capacidad de recursos que conseguía movilizar. Se debe advertir y resaltar que no se trata de hidalguía, nobleza o de fenómenos relacionados con ella, el estatus se obtiene en el mercado relacionar y a la vez tiene profundas consecuencias en la forma como tal mercado se configurara.

Entre 1799 y 1800 el sobrecargo del comerciante Girard de Filadelfia utiliza como consignatario a la casa comercial de Lasa y Cuesta. El comerciante estadunidense, uno de los más ricos de Filadelfia y de origen francés, ya había empleado a Lasa con anterioridad. Se dice además que el comerciante Pierre Thomas Denis (originario de Nantes) participaba con $2.5 \%$ de interés en la firma de Santa María y Cuesta y Lasa. Las operaciones entre la casa de Filadelfia y la de La Habana no se restringían a 
la consignación de mercancías; se sabe que el sobrecargo le entregó un crédito de 20000 dólares a Denis para ser utilizado en cualquier parte del continente advirtiéndole a Girard que cuando hubiese desembolsado tal suma a las órdenes de Denis le comunicase la manera en que quería que le fuese reembolsado el dinero en La Habana por las casas comerciales que se habían obligado a hacerlo. En abril de 1800, el mismo Denis viaja a Filadelfia llevando una carta encriptada dirigida a Girard. En ella se comunicaba que este, quien llevará la carta, tenía órdenes para recibir 30000 dólares que habían sido enviados y consignados como si fuesen propiedad de Girard pero que en realidad pertenecían a la casa de Lasa y Santa María Cuesta. Se hacían dos ofertas a Girard para que decidiese cuál le parecía la más conveniente. Por un lado, le era ofrecido un contrato de 6000 barriles de harina, carne y cerdo a entregar sobre el muelle libre de derechos y comisiones; por el otro, podía en su lugar tomar una comisión de $25 \%$ en la operación. Debía considerar en sus cálculos $70 \%$ de gastos en las harinas vendidas en la isla a precios que rondaban los 20, 26 o 21 dólares. Diferentes tipos de cálculos, toma de decisiones y de operaciones que se tienden a envolver bajo el apelativo de contrabando.

Ahora bien, a pesar de los diferentes tipos de operaciones Girard no encontró problemas en cambiar de consignatario en el momento que le pareció más apropiado. La decisión sin lugar a dudas estaba relacionada con la información comunicada por su sobrecargo, quien antes de dejar la isla en octubre de 1800 le aconsejaba enviar un nuevo sobrecargo. La correspondencia indica que Lasa y Dobignie habían tenido algunos malentendidos. En noviembre, Sebastián Lasa escribía una carta a Girard comunicándole de la nueva llegada del Good Friends, así como de las actuaciones del nuevo sobrecargo, quien le había expuesto a Lasa que, a pesar de que se le habían consignado las anteriores embarcaciones, esta vez Girard no había dado indicaciones expresas por lo que el sobrecargo se valdría de los "amigos" de él en La Habana. El nuevo consignatario elegido era el ya mencionado Tomas Gimbal. Lasa entonces le propuso al sobrecargo la compra del cargamento entregándole 26500 pesos a los ocho días y una cantidad parecida a los siguientes ocho; pero a pesar de proponerle 53000 pesos, este había preferido vender a por menor la carga tal vez con la esperanza de obtener un poco más de ganancias. Era verdad que tal vez podría conseguirlas, pero al costo de un largo tiempo de espera. Lasa no dudó en escribir una carta a Girard para comunicar su insatisfacción. No sólo resaltaba el grueso capital que poseía y una renta de 30000 a 35000 pesos que le generaban sus ingenios ${ }^{16}$ sino que además señalaba que había hecho muchas cosas por la casa de Girard aun sin recibir las

\footnotetext{
${ }^{16}$ PHS, Girard Papers, 15 de noviembre de 1800; AGI, Ultramar, 314.
} 
comisiones debidas. En otra carta, al parecer respondiendo a la decisión de Girard respecto al cambio de consignatario, Lasa le deja en claro que la situación no lo habría afectado tanto si la carga hubiese sido consignada a otra casa comercial que el sobrecargo había encontrado por conveniente y si se hubiese tratado de un nuevo barco que no hubiese sido enviado a la isla previamente pero no del Good Friends. Incomodaba el hecho de que los americanos entregaran consignaciones a comerciantes en la isla que ni siquiera habían recibido la primera de la península. Las razones que Lasa presenta son llamativas: su capital material, su capital simbólico (capacidad de hacer favores incluso "desinteresadamente") y su reputación. Rumores de no recibir consignado un barco hecho con anticipación, sin duda afectaba su imagen. No menos de considerar era el hecho de que los estadunidenses entregaran consignaciones en la isla a agentes que ni aún habían recibido la primera de España. ${ }^{17}$

Se trata de varios factores que intervienen en la selección de un agente o en la decisión de cambiarlo. El 30 de octubre de 1816 llegaba a La Habana un barco propiedad de los Bryan and Sturgis ya mencionados, el Jacob Jones. En este venía como sobrecargo Samuel Curson que se había desplazado a La Habana con dos objetivos. El primero, había sido encargado por Bryan and Sturgis de la venta del Jacob Jones. En mayo del mismo año los comerciantes de Boston le habían consultado a Murdock sobre la posible venta de tal embarcación. Este último encontraba serias dificultades para realizar la transacción comercial debido a que el único comercio "now pursued from this place" era aquel de la costa de África para el cual se daba preferencia a las goletas, e incluso para este tipo de embarcaciones cualquier transacción resultaba bastante enmarañada debido a la incertidumbre en la que se encontraba la continuación de tal comercio. El segundo de los objetivos de Samuel Curson era instalarse como comerciante en el puerto azucarero. En octubre, Curson escribía que había consignado el negocio de la Jacob Jones en las manos de Drake, "in the belief that Mr. Murdock and Mr. Seul would do it better than any other here". Curson aseguraba en su carta que Mr. Murdock era una persona "very much of my satisfaction". Le apuntaba además que todavía no había determinado cómo sería su instalación en la isla, y que por tanto emplearía la casa de Santiago Drake "until I can arrange complete to my satisfaction and so that I can give a strong assurance to my friends that the business will do well". ${ }^{18}$

En su carta escrita una semana después las cosas mudan de tono radicalmente. Empieza por comentar la imposibilidad de establecerse en la

${ }^{17}$ PHS, Girard Papers, 30 de abril de 1801.

${ }^{18}$ Massachusetts Historical Society (en adelante MHS), Hopper Sturgis Papers, Ms-n 1435, caja 7. 
casa de Antonio Frías, ya que los socios que hacían parte de dicha sociedad no le parecían capaces de hacer las cosas que sus amigos le pedirían "they neither do their business well nor promptly". Le comentaba que si el principal socio de la casa, Antonio Frías, hubiese convenido "[to] make a separate establishment, I would have done it as he is opulent and honorable". Se debe decir que ya desde el 22 de febrero de 1815, los Bryan and Sturgis habían recibido una carta circular de Antonio Frías en la cual les participaba del establecimiento de su casa comercial en el puerto de La Habana. ${ }^{19}$ Es imposible asegurar si esta tenía alguna relación con el viaje de Curson. Línea seguida descubría el funcionamiento de la casa comercial de Santiago Drake, la cual aparecía ahora bajo una perspectiva bastante diferente. Incluso a pesar de que Drake podría estar dispuesto "to let me make use of them", esta opción le parecía más bien desventajosa en razón de que tal casa comercial, a su modo de ver, estaba ya sobrecargada de operaciones. De igual manera, le confesaba que alguien que vivía en la casa de Drake "assures me they have more than they can well attend to and that it is sometimes a serious inconvenience". Al parecer, ya había encontrado una persona que llenaba sus expectativas, a la que le había explicado sus planes, y de quien estaba a la espera de una respuesta.

Aquí aparecen ciertos hechos valiosos que permiten aprehender los factores que intervenían en el mantenimiento de viejos socios o la posible selección de nuevos. Los acontecimientos que rodean la venta de la embarcación Jacob Jones se mezclan con los de la instalación de Curson con una casa comercial en La Habana diferente de la que Bryan and Sturgis acostumbraban a emplear, aunque estos últimos se valieron de diferentes personas en la isla. La embarcación había sido comprada por el Consulado por 20000 dólares, al parecer para ser llevada a Cádiz y después cargada para comerciar en la costa de Africa. Por las cartas de Murdock y Curson se infiere con claridad que había sido el primero quien había ejecutado la venta y quien estaba encargado de cobrar el dinero.

El 24 de noviembre de 1816 se envió desde La Habana una carta de invitación de la casa comercial Miralla y Cía. a la firma Bryan and Sturgis. Se trataba de José Antonio Miralla, originario de Córdoba en Argentina y quien se hallaba residiendo en la isla. Se notificaba que Curson lo conocía desde tiempo atrás en Lima y que este sabía que Miralla era una persona de integridad, resaltando algo de mayor cotización, Miralla era sin duda una persona "whose talents have acquired him the friendship and support of the first persons in this island". A Miralla se asociaba George Knight quien había estado residiendo en La Habana durante dos años, dedicado a transacciones y negocios de comisión, y de quien no se necesitaba

${ }^{19}$ MHS, Hopper Sturgis Papers, Ms-n 1435, caja 2. 
dar mayores recomendaciones pues las ganancias que le había generado a un comerciante como Lee podían hablar por sí solas. El otro socio sería Samuel Curson, quien comerciaba con los territorios españoles desde al menos 1800, y habiendo vivido seis años en la península y sus colonias.

En enero de 1817, después de haber recibido una carta de Boston donde Bryan and Sturgis admitía su gran satisfacción con las ganancias dejadas por la venta de la embarcación Jacob Jones, Curson escribe que también estaba bastante complacido con el valor logrado pues las opciones del mercado no eran las mejores. En el mejor de los casos, escribe, la venta no se realizaría por encima de 15000 dólares. El valor obtenido se debía a una sencilla razón que explica en esa misma carta. No podía haber duda de que su socio Miralla había sido "particularly serviceable" "through his influence with many of the leading people in the Chamber of Commerce (Consulado)". Era a esta influencia y a la amistad que le había profesado el intendente (no es claro si a él o a Miralla) desde su llegada que se debía la diferencia de 5000 dólares. Es interesante cómo en sus cartas Curson resalta una y otra vez la posición de poder o de influencia de Miralla respecto a otros comerciantes en la isla, con los cuales se podrían establecer negocios. ${ }^{20}$

Sin embargo, Curson es bastante cuidadoso en el momento de insinuar cualquier cosa en contra de Drake, tal vez en un intento de evitar proponer a los Bryan and Sturgis entrar en negociaciones exclusivas con nuevos socios y retirar del todo sus negocios a la casa de Drake: "I shall not exact that you should take your business from Drake and give it to Miralla and \& as we are on so cordial a footing with them and receive from them such favours that we should feel pain rather than pleasure at knowing anyone has left them for us". Curson preveía que Drake no lamentaría verlos tomar a ellos una parte de los negocios de comisión "provided it be not of old friends". De acuerdo con la información que ya había remitido, estos reconocían tener más negocios de los que podían realizar y, al contrario, podrían incluso estar contentos de ver tomar a Curson parte de las consignaciones que llegasen a La Habana. Y remarcaba que presumía se referían a aquellos negocios más problemáticos y que dejaban menos ganancias para el consignatario, como por ejemplo, maderas, barcos y remesas de mieles. En seguida compara dos casas comerciales de la ciudad: la de Santiago Drake y la de Packard, Gowen and Frías: "The former has got to be too great men to deal with as merchants, and the latter has not their business well regulated. Both have too many irons in the fire, and the latter has not head you can look to and make responsible for the execution of business." La selección hecha por Curson muestra con claridad los dife-

${ }^{20}$ MHS, Hopper Sturgis Papers, Ms-n 1435, caja 7. 
rentes cálculos que se consideraban en el momento de entrar en contacto, establecer una sociedad, o entregar una consignación a un agente particular. No obstante la lectura de la casa Packard, Gowen and Frías que Curson hacía, esta fue empleada por Brown and Ives, comerciantes de Providence quienes estuvieron activos en el comercio con Cuba durante las dos primeras décadas del siglo XIX. La sociedad había sido empleada después de 1817 pues Brown había utilizado como consignatario a John Reynolds durante los primeros años. Entre 1816 y 1817, Brown and Ives sólo enviaron algunas cartas el 25 de abril, el 10 de junio, el 23 de agosto, el 19 de diciembre, y sólo tres durante el primer semestre de 1817, a pesar de las quejas de sus consignatarios por el poco interés que estos mostraban. No obstante, a pesar de la que parece ser cierta apatía por mantener contacto cercano con la casa comercial instalada en La Habana, es precisamente en abril de 1817 cuando los agentes en Cuba escriben una carta para Providence que tenía como función agradecer a sus amigos el hecho de haberlos recomendado a Mr. Aborn and Jackon, de quienes había llegado a la isla un barco comandado por el capitán Arnold.

El estatus, sin lugar a dudas, desempeñó un papel importante que ha sido infravalorado. Es importante preguntarse cuán eficaz sería contar con agentes con un alto grado de reputación (ya por su honradez ya por su capacidad de trabajo) o de alguien de confianza por corresponder con supuestos patrones de identidad, si se trata de agentes sin ninguna capacidad de movilizar favores (pero, sobre todo, de disponer de un alto valor en el mercado de favores, lo que se demostraría por la cantidad de agentes dispuestos a hacer favores sin recibir algo a cambio y su obligación de hacer favores a un pequeño y altamente valorado número de agentes), sin contactos, y sobre todo, contactos de valor. Este mercado de favores y el estatus (capital simbólico) se relaciona con una selección oportunista de los agentes, sin la cual las mercancías con dificultad pueden circular.

\section{EL MERCADO DE COSAS Y LA TOMA DE DECISIONES}

La paulatina transformación de La Habana en una isla-plantación tuvo consecuencias importantes en el abastecimiento del puerto de La Habana. De acuerdo con un censo de 1778, la ciudad alcanzaba un total de 40737 habitantes, convirtiéndose en el puerto más grande del mundo español americano y en la tercera ciudad más poblada de América, sólo por detrás de México y Lima (Kuethe, 1991, p. 13). La población de la ciudad estaba constituida por $60 \%$ de blancos, $23 \%$ esclavos y $17 \%$ negros y mulatos libres. En 1792, la ciudad contaba con 51307 habitantes y en 1817 vivían 84075 personas (Johnson, 2001; Sagra, 1831, pp. 4-7; Vázquez, 2008). 
Una ciudad de una dimensión tal, que no podía abastecerse con facilidad de su hinterland, necesitaba sin duda de la importación de la mayor parte de lo que consumía (Amores, 2000; Fernández, 2000, 2002; Sagra, 1831). Fueron los comerciantes estadunidenses quienes se encargaron de abastecer La Habana, en especial, durante los periodos de guerra de España con otras naciones. Ahora bien, en general, se asocia a los estadunidenses como los más interesados en la extracción de plata, o deseosos por convertir el puerto en el mercado de los molinos de Pensilvania. Es verdad que La Habana absorbió inmensas cantidades de harina producidas en Estados Unidos, la mayor parte de estas reexportadas a través de España. ${ }^{21}$ Pero, como demostró cuantitativamente Cuenca-Esteban (1984), tomando en cuenta el tonelaje y las exportaciones, los comerciantes estadunidenses al parecer no fueron tan malos socios como se tiende a describir en la historiografía. Esta segunda sección se ocupa no tanto de las mercancías enviadas a la isla y sí del proceso de toma de decisiones (bajo condiciones y cálculos determinados y bajo el tipo de presiones descritas en la primera sección) que los agentes llevaban a cabo para remitir los beneficios ocasionados por las consignaciones. Se trata de prestar atención a los factores que intervenían en la toma de decisiones y de ir más allá de la simple presentación de los estadunidenses como extractores de plata y de introductores de harina.

\section{¿ÚNICAMENTE PLATA Y HARINA?}

¿Pesos de plata o azúcar? Aunque la respuesta a simple vista parecería evidente, la toma de decisiones en la selección y envío incluye una amplia variedad de factores y cálculos. Se puede dar una respuesta aproximada a la pregunta con las operaciones del comerciante Girard entre 1799 y 1800 (véanse gráficas 1 y 2).

Un seguimiento detallado a toda la correspondencia mantenida entre Dobignie y Girard permite saber las cantidades de azúcar (entre otras mercancías) y de pesos de plata remitidos a Filadelfia. Se trataba de las ganancias correspondientes a tres embarcaciones Good Friends, Voltaire y Liberty, llegadas en noviembre de 1799. Desde febrero hasta finales de agosto fueron embarcados 244796 dólares en mercancías y 118800 dóla-

${ }^{21}$ De las importaciones existen tres artículos que llaman de inmediato la atención: alimentos $(40 \%)$, textiles $(24 \%)$ y esclavos $(15 \%)$. Los alimentos constituyen el porcentaje más elevado, alcanzando casi la mitad del valor total de las importaciones. En general tres artículos constituyen las mayores importaciones: la harina $(15 \%)$, el vino $(8 \%)$ y la carne $(5 \%)$. La harina sin lugar a dudas fue el producto de mayor peso. La harina embarcada desde las colonias (lo que quiere decir aquí principalmente Estados Unidos) decrece desde 1729539 en 1805 hasta 1010760 pesos (Fernández, 2000). 


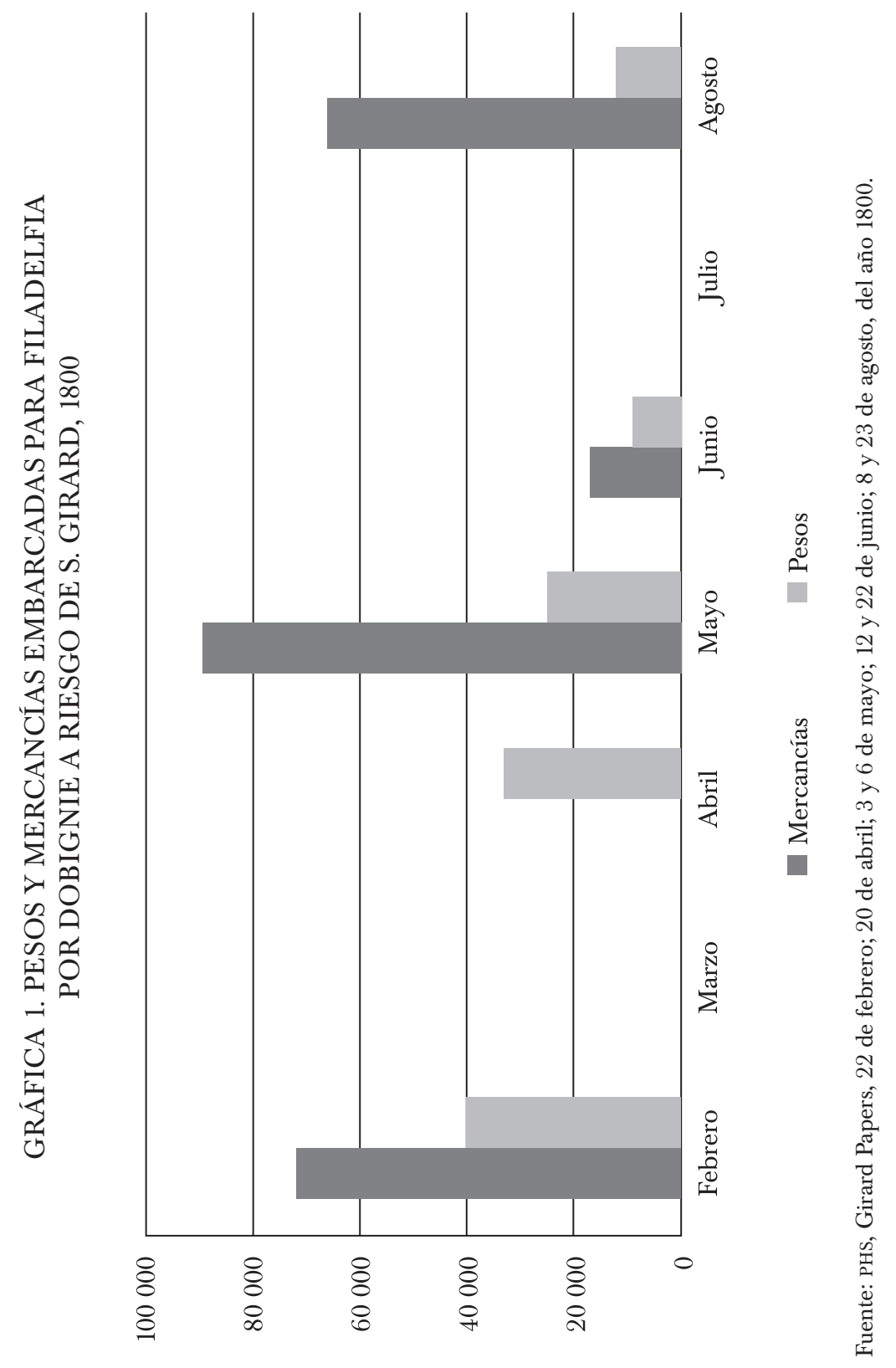




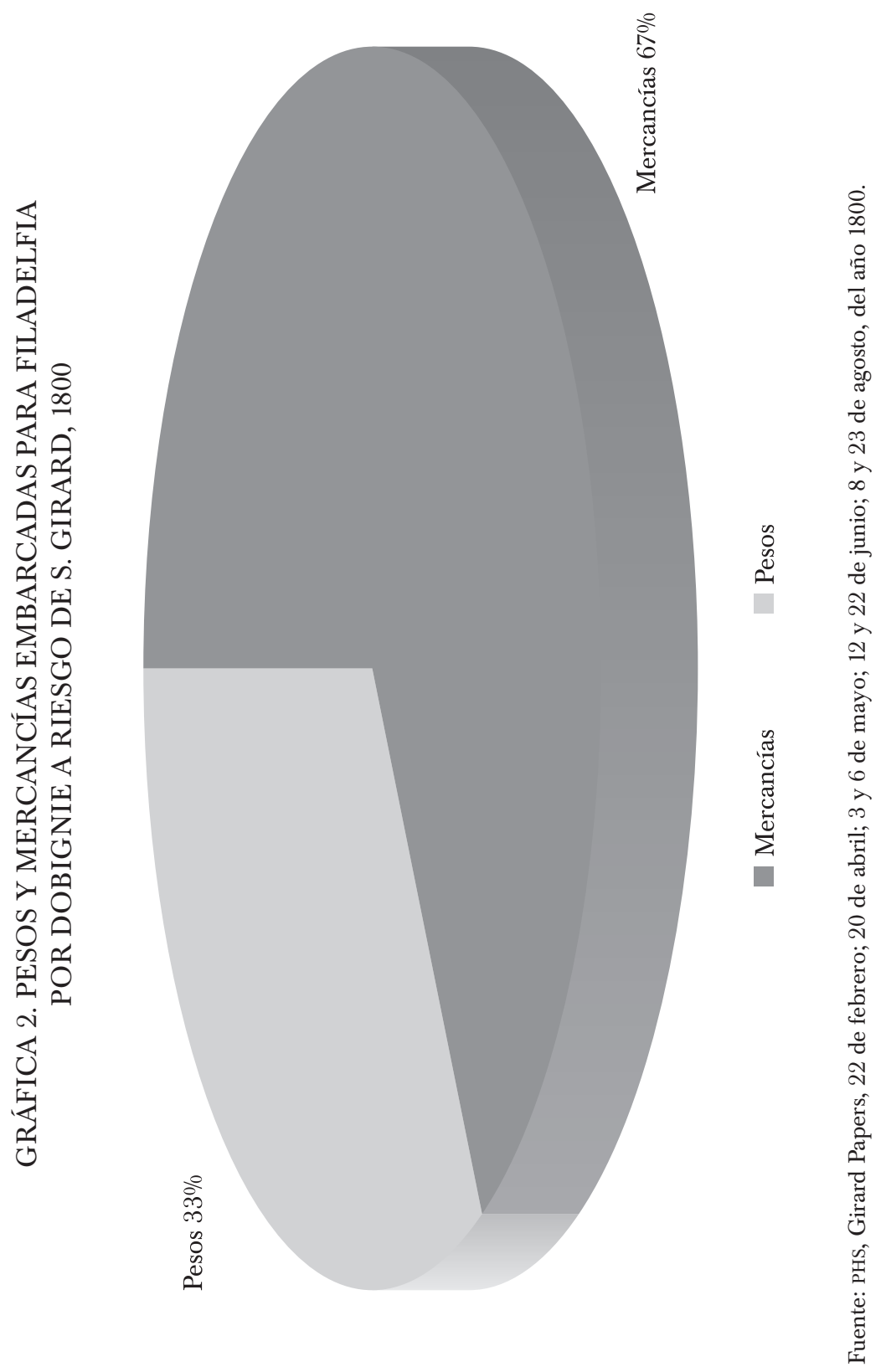


res en pesos fuertes, lo que quiere decir que en un lapso de nueve meses la casa de Girard giró 363596 dólares, de los cuales $67 \%$ le fueron remitidos en mercancías y $32 \%$ en plata. Sólo un mes después de haber llegado a la plaza informaba de las terribles condiciones del mercado de azúcar, pues debido a la llegada de varios barcos estadunidenses los precios se habían incrementado. El problema en remitir con rapidez las embarcaciones no la atribuía a la falta de dinero en el mercado sino a los precios del azúcar. ${ }^{22}$ Al finalizar enero, advertía que aunque sus deseos eran enviar pronto de vuelta la Liberty, el alto precio del azúcar le impedía completar la carga teniéndola que mantener por más tiempo en el puerto. ${ }^{23}$

A mediados de febrero ya había conseguido carga para dos de los barcos, el Liberty llevaría 800 cajas de azúcar mientras el Good Friends estaría cargado con 1000 cajas. ${ }^{24}$ En total, el Good Friends volvería cargando 40087 dólares en productos y 21000 dólares en plata, mientras el Liberty llevaba 31865 dólares en productos y 20000 en moneda. Lo que quiere decir que ambos barcos llevaban entre 61 y $65 \%$ del valor de la carga en productos. Lo que quiere decir también que, a un precio de cuatro dólares por caja, el cargamento habría de producir un flete de 7200 dólares, lo que equivale a $18 \%$ de la plata cargada. Como se ve en los dos casos, las ganancias de los fletes en el tránsito de Cuba a Filadelfia no eran despreciables; fletes que debían incrementarse con el transporte del mismo azúcar desde Estados Unidos a los mercados europeos. Estos cálculos son importantes en las resoluciones que debían tomar los agentes, pues en las cuentas se contabiliza a perfección cuáles son los gastos producidos por las embarcaciones, y habría que buscar la manera de cubrirlos. ${ }^{25}$

Pero en ese momento el mercado del azúcar toma otro rumbo. Girard es advertido desde Europa de la caída del precio del producto, lo que lo hace prevenir a su sobrecargo demorar el envío de las embarcaciones para frenar la llegada a Filadelfia y así impedir que el precio se desplomase en el puerto americano. Los cálculos del patrón diferían de los de su sobrecargo, que en La Habana a pesar de estar enterado de los cambios preveía que sus repercusiones no podrían tener un efecto directo sino hasta la primavera. A la par, se arriesgaba a vaticinar que a pesar del gran stock de azúcar disponible en el mercado habanero, las exportaciones se retomarían pronto, aunque no a los mismos niveles que el año precedente, mejorando las condiciones de la demanda de productos y las ganancias en las ventas. Pero son todavía de mayor interés su interpretación de los actores en el mercado cubano. Ahora

\footnotetext{
${ }^{22}$ PHS, Girard Papers, 1 y 10 de enero de 1800.

${ }^{23}$ PHS, Girard Papers, 22 de enero de 1800.

${ }^{24}$ PHS, Girard Papers, 15 de febrero de 1800.

${ }^{25}$ PHS, Girard Papers, 1 de abril de 1800.
} 
que los precios del azúcar habían caído, el mercado tomaba otro rumbo. Los capitalistas, quienes especulaban con azúcar y quienes eran bastante numerosos tornarían su atención hacia la consignación de las expediciones extranjeras. ${ }^{26}$ Con precios altos del azúcar, los comerciantes en La Habana prestaban atención a la compra y reventa para los comerciantes americanos. Cuando el precio caía competían por la consignación de mercancías. Por su puesto, podía ser que en ese momento, los dueños de ingenios buscasen retener sus stocks en las plantaciones en un intento de frenar la caída de los precios. O como expone el sobrecargo, "los propietarios se dan la mano".

Lo que sí evidencia la correspondencia del sobrecargo es la multitud de factores que intervienen en las decisiones tomadas por los agentes como respuesta ya sea a las condiciones del mercado o a sus intereses particulares. Disponibilidad de dinero en el mercado, intención por parte de los dueños de ingenio para retener el azúcar en stock el máximo de tiempo intentando frenar la caída de los precios, especulaciones con el azúcar, posibles ganancias dejadas a través de la comisión de venta y compra de azúcar o del cambio de moneda, necesidad de cubrir los costos de los barcos empleados, etc. Todos estos fenómenos deben ser considerados y analizados con más detalle para comprender las acciones de los agentes en un mercado tan inestable como el de La Habana para ir más allá de las narrativas que hablan sin cesar de operaciones encubiertas. Por ejemplo, el 1 de septiembre, Dobignie comunica que había cambiado de idea respecto a 168 cajas de azúcar que había comprado previamente para ser remitidas a bordo del barco Experiment, había optado mejor por vendérselas al joven comerciante Gourjon para tener así más dinero en efectivo. ${ }^{27}$ Poco se sabe de la manera como estos agentes tomaban sus decisiones respondiendo a las condiciones del mercado y a las cambiantes órdenes recibidas desde ultramar. La situación es mucho más compleja, y desde esta perspectiva microeconómica se deja ver cómo el mercado habanero era visto más allá que un simple "abastecedor de plata" para el mercado americano.

\section{Mieles y telas de Asia en el CARibe: LAS NECESIDADES DEL MERCADO AFRICANO}

Pero no era sólo azúcar lo que los comerciantes americanos buscaban en la isla. Existía otro producto de gran importancia. El estado de Rhode Island

${ }^{26}$ PHS, Girard Papers, 23 de febrero de 1800. Sobre la especulación con el azúcar al interior de la isla, un tema pasado por alto pues siempre se contabiliza como producto de exportación, véase Bohorquez (2016, pp. 381-385).

${ }^{27}$ PHS, Girard Papers, 1 de septiembre de 1800. 
(puertos como Newport, Bristol y ciudades como Providence) importaba grandes cantidades de mieles. En 1770, se importaba más de un millón de galones, de los cuales se destilaba 79\%, parte del cual tenía como destino los puertos de África. Las islas del Caribe brindaron a los comerciantes de Rhode Island un tipo de mercancía que les permitía invertir en el tráfico de esclavos. La producción de ron sólo era superada por las destilerías de Massachusetts (Coughtry, 1981, p. 15). Aunque no hay duda de que el refinamiento del azúcar constituía el corazón de las actividades del sistema de plantación, los dueños de ingenios en el Caribe sabían muy bien que la destilación de licores ayudaba a cubrir al menos dos terceras partes de los costos anuales del funcionamiento de un ingenio. Esta era la principal razón por la cual los hacendados invertían sus capitales en la adquisición de utensilios altamente costosos y necesarios para la transformación de las mieles en bebidas de diferente graduación alcohólica, utensilios que en la mayor parte de los casos eran importados de Europa. Un ingenio que producía 1000 cajas de azúcar producía también 4000 barriles de miel, los cuales a un precio de siete a ocho reales le aseguraban anualmente 4000 pesos al propietario para atender los costos de funcionamiento del ingenio. ${ }^{28}$ Reducidos a aguardiente o ron, los mismos barriles doblaban las ganancias. Sin embargo, los cubanos encontraron serias dificultades para darle salida a su posible producción de aguardientes durante largo tiempo. Los americanos se convirtieron en excelentes compradores de mieles.

El barco Plutus, propiedad de Bryan and Sturgis, tocó de nuevo el puerto de La Habana a finales de mayo de 1816. Esta vez la carga le fue consignada a Santiago Drake, a quien también se le habían consignado en el mismo mes los cargamentos del Tiger y el John Smith. Habían sido enviadas instrucciones para que el tornaviaje se hiciese con mieles de la mejor calidad, y de no ser posible se buscase flete o se vendiese el barco. Las tres indicaciones pueden ser inferidas de la carta de réplica enviada por Murdock. Respecto a la calidad de las mieles, el comerciante de La Habana le replicaba que se tomarían todos los esfuerzos para adquirirlas, a pesar de que la situación era bastante ardua debido a que la demanda era impresionantemente alta. Por ello "when this article is much sought after as it now is and will continue to be choice or selection is out of the question". En un mercado de tales condiciones la mejor opción era evitar que un artículo de extrema mala calidad fuese adquirido. En general, se trataba de una cuestión de suerte, pues se podía al mismo tiempo y de la misma persona comprar al mismo precio cargas con parcelas de buena y mala calidad, lo que hacía que los barcos pudiesen conducir un producto de gran diferencia en la cualidad pero infelizmente adquiridas al mismo precio. $\mathrm{Y}$

${ }^{28}$ AGI, Santo Domingo, 2195. 
le subrayaba "this circumstances may appear to you in America a strange indifference". Respecto a la posibilidad de enviar barriles, Murdock procedía a explicar la imposibilidad de realizar tal adquisición. De acuerdo con él, los barriles eran fabricados por las mismas personas que transportaban las mieles desde los ingenios hasta el puerto, y su venta era un negocio tan lucrativo como la misma venta del artículo extraído de la caña de azúcar. Por esta razón, intentaban vender todo en conjunto. Era posible, no obstante, conseguir negociar bajo ciertas condiciones. Por ejemplo, "they purchase our stock which they sell to us again made into casks if we require of them the molasses. They will not supply it on any other terms. Sometimes they do an exchange on hogsheads with a consideration or to fill our own casks for a certain stipulated sum per cask". ${ }^{29}$

De acuerdo con la carta del 6 de agosto de 1816, se enviaba a cuenta y riesgo de los dueños del barco Plutus mieles por un valor de 11029 dólares, mientras que la carga del barco vendida hasta el momento era de 2495 dólares, con lo cual, quedaba un balance a favor de Drake de aproximadamente 8922 dólares. ${ }^{30}$ El 28 de octubre se enviaba un listado de los valores de las mercancías de cada barco. Del Plutus se habían realizado ventas por un valor de 7975 dólares. Al tomarse sólo el cargamento del Plutus, quedaba un saldo a favor del comerciante de La Habana, pero cuando se hacían las cuentas junto con las de las otras embarcaciones involucradas en el trayecto, el comerciante de Boston quedaba con un saldo a favor de 3783 dólares. ${ }^{31}$ Otra factura y cuenta del Plutus fue enviada el 12 de enero de 1817. De acuerdo con estas nuevas cuentas, se habían embarcado mieles por 11619 dólares mientras el producto de las ventas de la carga transportada por dicho barco era hasta el momento de 8126 dólares. Quedaba así un saldo a favor del comerciante de La Habana de 3935 dólares. No obstante, si se consideraba el balance en general, el cual comprendía las ventas de las cargas de los demás barcos, incluyendo el último en llegar a la isla llamado Jacob Jones, las cuales habían sido de 9931 dólares, la casa comercial de Nueva Inglaterra quedaba con un saldo a favor de 9719 dólares. $^{32}$

Existe una cierta complementariedad. Mientras los americanos requerían las mieles para fabricar los rones necesarios para los mercados africanos y para el consumo interno, una vez puestas en marcha las expediciones nacionales hacia el continente africano, los comerciantes cubanos o los agentes de comerciantes peninsulares en la isla necesitaban gran cantidad

\footnotetext{
${ }^{29}$ MHS, Hooper Sturgis Papers, Ms-n 1435, caja 6.

${ }^{30}$ MHS, Hooper Sturgis Papers, Ms-n 1435, caja 6.

${ }^{31}$ MHS, Hooper Sturgis Papers, Ms-n 1435, caja 7.

${ }^{32}$ MHS, Hooper Sturgis Papers, Ms-n 1435, caja 7.
} 
de textiles. Una abundante cantidad de trabajos ha mostrado la importancia de las manufacturas asiáticas, textiles de algodón, y la alta demanda que alcanzaron en los mercados especializados en la transformación de humanos en esclavos. Eran bien sabidas las dificultades de comerciar en las costas de África sin una amplia variedad de este tipo de coloridos textiles de algodón. ${ }^{33}$ Para el caso cubano, los comerciantes americanos se convirtieron en proveedores de este tipo de mercancías, lo que implicaba conectar La Habana con puertos lejanos como Calcuta y Macao, al tiempo que transportaban importantes cantidades de mieles fuera de la isla. En la correspondencia se habla de una amplia variedad de textiles como baftas, gurrats, mamoodies, nankeens. El comportamiento del mercado de textiles estaba determinado por dos razones: primero, la partida de expediciones para África y la llegada de estas expediciones con buenos resultados de negociación; segundo, las presiones para dar fin al tráfico transatlántico de hombres. Los años 1816-1820 son interesantes en este sentido. Durante 1816 el mercado de La Habana parece haber sido altamente favorable a la importación de tejidos de Asia. Todo lo contrario sucede un año después, cuando el mercado parece estar inundado de estas mercancías y resulta verdaderamente difícil para los agentes pronosticar cómo sería su comportamiento. Es posible hacer un doble seguimiento a lo que acontecía en el mercado habanero con este tipo de manufacturas contrastando la información que Packard, Thomas and Gowen enviaban hacia Providence y los pronósticos que Murdock remitía hacia Boston. Los segundos siempre tienden a ser muchos más largos y con descripciones bastante detalladas. Su información sobre el comportamiento de la demanda parecía bastante rigurosa. La casa comercial Bryan and Sturgis mantenía fuertes vínculos con la compañía mercantil de Boston J. and T. Perkins, quienes a su vez interactuaban comercialmente en Cantón a través de Samuel G. Perkins, este último, tal como trasluce en la correspondencia de Bryan and Sturgis también mantenía negocios con Richard Hinckley en La Habana. Brown and Ives también tuvieron contactos con Perkins and Company, constituida por William Paine y John P. Cushing quienes trabajaban en Cantón como representantes de la casa comercial de Boston. ${ }^{34}$

No hay duda de que en el primer semestre de 1816 una enorme cantidad de manufacturas asiáticas había afluido hacia la isla. Es probable que el exceso de la oferta se debía a la terminación del conflicto anglo-americano que había iniciado en 1812. En mayo de 1816, se aclara que a pesar

\footnotetext{
${ }^{33}$ Sobre la circulación de manufacturas de algodón a escala global durante la revolución industrial, véanse Beckert (2014), Riello y Tirthankar (2009), Riello y Parthasarathi (2011), Ferreira (2001) y Machado (2014).

${ }^{34}$ John Carter Brown Library (en adelante JCB), Brown Business Papers, cajas 275 y 276.
} 
de las abundantes importaciones, las manufacturas de la India continuaban teniendo un buen precio. Textiles de colores de China, azul marino y negro estaban en demanda; además de estos, los textiles comprados con destino al mercado africano "sell to good account here". Por su parte, en su carta del 10 de mayo, Murdock advierte de las dificultades a las que se enfrentaba para vender los productos importados de Asia. De acuerdo con él, los comerciantes de la ciudad pronosticaban grandes importaciones y por tanto intentaban comprar con bastante precaución, "I hardly know what I might give you reason to expect". Unas semanas después informaba Murdock las enormes dificultades para realizar ventas de las mercancías pertenecientes a la firma Bryan and Sturgis. Los mercaderes continuaban convencidos de que la oferta de estos productos no pararía de fluir, por lo que o no estaban muy interesados en ir a los almacenes o hacían ofertas irrisorias que era imposible aceptar "They must return again of their own accord, should we feel disposed afterwards to accept the terms first offered, and expect to get them". Por una parte, los comerciantes buscaban tener los mejores precios, colocando a la baja la demanda. Por la otra, el agente debía decidir si vender en las condiciones que estos proponían (con miedo de que llegasen más remesas); a lo que se sumaba los costos y pérdidas causados por el almacenamiento de mercancías delicadas que al menor defecto perdían gran parte de su precio. A ello debía sumarse que una mayor disponibilidad de telas destinadas para el consumo interno hacía que las mujeres las catalogasen como fuera de moda. La advertencia era clara "should the advices respecting this and indeed of all other articles of East India manufacture soon reach the United States, I trust a stop will be put to shipments of any of them to this place". ${ }^{35}$

Para el 18 de julio de 1816, la advertencia era clara "Everything like China silks is a complete glut. East India or Calcutta goods suitable for the coast have had a brisk demand." Estos productos estaban siendo vendidos por encima de los precios que le adjuntaba en la lista y "from appearances will continue to find a pretty steady sale". La razón era simple, las expediciones hacia la costa de África estaban siendo puestas en marcha y había grandes esperanzas de que el privilegio de continuar el comercio de esclavos fuese renovado. Sólo una semana después Packard, Thomas and Gowen envía una carta a Brown and Yves insistiendo sobre la demanda de productos destinados para la costa africana. Advierte que el mercado de la isla parecía estar mejorando para los productos estadunidenses mientras que los productos de la isla estaban en declive. Esperaban un cambio favorable en el estado del mercado, particularmente respecto a aquellos

${ }^{35}$ MHS, Hooper Sturgis Papers, Ms-n 1435, caja 6. 
textiles importados para el mercado africano, en especial, baftas azules y gurrats, los cuales estaban en demanda y dejarían buenas ganancias. ${ }^{36}$

El 28 de noviembre Packard, Thomas and Gowen aclaraba que había en stock una alta cantidad de lo que llamaba textiles de Calcuta y Goa, aproximadamente 500 o 600 fardos generando, en consecuencia, una baja demanda. La falta de interés que se registraba hacia el 3 de diciembre se debía a las pocas expediciones que habían sido armadas para la costa de África. El tráfico de esclavos parecía estarse tornando menos productivo "the spirit of Enterprise is evidently of late less sanguine. Still that trade will be pursued by many and large quantities of goods will be required, but what I mean to say is that in sales we shall not find the same facili-

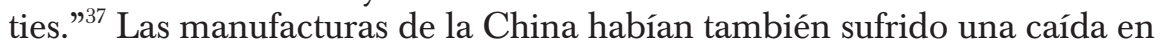
su precio, sobre todo los manquín, debido a la interrupción del comercio con Veracruz. Se desprende de allí que mientras los textiles de la India eran destinados al comercio con África, parte de las manufacturas de China eran destinadas al mercado mexicano. Tanto Murdock como Packard, Thomas and Gowen advierten del mismo hecho a finales de diciembre; de acuerdo con los últimos, los manquín estaban casi en exclusiva destinados para Veracruz. ${ }^{38}$

\section{Estado del mercado: no sólo precios y calidad de la información}

La casa Packard, Thomas and Gowen informaba continuamente entre el 22 de marzo de 1812 y noviembre de 1819 sobre el estado del mercado. La correspondencia se mantiene por siete años, aunque en realidad se trataba de una correspondencia bastante desigual, pues esta sostenía una frecuente expedición de cartas informando a los comerciantes en Providence de los precios del mercado que pocas veces encontraba respuesta por parte de Brown and Ives. De acuerdo con lo que se deduce de la correspondencia de sus agentes en La Habana, la firma de Nueva Inglaterra no respondía y tampoco parecía estar muy interesada en el mercado de la isla. Es más, sus consignatarios escriben una y otra vez para solicitar órdenes respecto a lo que debían hacer con el producto de la venta de algunas consignaciones, por lo que parecen estar verdaderamente impacientes por una respuesta.

El mercado de La Habana cambiaba de modo inesperado, lo que hacía complicado acertar en cualquier predicción conveniente. Los patrones

\footnotetext{
${ }^{36}$ JCB, Brown Business Papers, caja 265.

${ }^{37}$ MHS, Hooper Sturgis Papers, Ms-n 1435, caja 7.

${ }^{38}$ JCB, Brown Business Papers, caja 265; MHS, Hooper Sturgis Papers, Ms-n 1435, caja 7.
} 
de los artículos de consumo y de exportación tendían a seguir tendencias opuestas. Como se ha descrito, es difícil encontrar, tanto en la correspondencia enviada hacia Providence como en aquella destinada a Boston, órdenes explicitas y frecuentes de remesas de plata. Es más, si hay algo que resulta difícil de encontrar al leer las cartas es justo las indicaciones donde se deje por explícito que como resultado de ajuste de cuentas se enviase el producto de la negociación exclusivamente en plata. La razón era sencilla: el azúcar, las mieles y el café pesaban más que la plata y generaban jugosas ganancias en razón de fletes. Esto interesaba a los comerciantes de Nueva Inglaterra, que de creer aquello que se dice en la correspondencia, en varias ocasiones enviaban mercancías hacia un mercado con precios bajos para poder obtener las ganancias de los fletes de ida y vuelta aun reconociendo las posibles pérdidas causadas por las ventas, o la incapacidad de colocar los artículos en el mercado con un precio mayor al de costo. Parece que en ocasiones los fletes dejaban ganancias más seguras que la propia venta de las manufacturas. De otro lado, estaban los agentes en la isla, que preferían enviar productos coloniales, pues a sus ganancias de comisión se sumaban aquellas dejadas por la compra y venta en el mercado doméstico.

Ahora bien, tal como relataba Curson, informar el estado del mercado no era sólo informar sobre los precios de una plaza. La tarea era mucho más enrevesada. No se trata de una simple circulación de la información y de las maneras de cómo tener acceso a ella. Se trataba, a decir verdad, de calificar el mercado con los adjetivos más precisos para dar una impresión exacta a sus socios sobre cuáles eran los mejores artículos que podían ser remitidos. Al mismo tiempo, sin embargo, se trataba de convencer a los socios para invertir en un artículo determinado, sobreexponiéndolos a los posibles beneficios que les dejaría una negociación determinada. Para esto era necesario ubicarlo temporalmente, invitándolo a actuar con rapidez. Se debe considerar, no obstante, que se recibía información sobre el estado del mercado de manera simultánea de varios agentes, por lo que el sistema generaba un mecanismo de autocontrol sobre las opiniones que los agentes transmitían. Al exagerar en la búsqueda de ganancias se podía caer en el riesgo no de generar mala reputación sino de ser castigado con la remesa de futuras consignaciones. De la manera que lo colocaba Curson "I shall soon send you advice on the moments you inquire for, few can answer well those question". Por ejemplo, de acuerdo con las listas de precios que se enviaban, la pimienta aparecía a 28 dólares "but this is on asking prices only, considerable has arrived and here are no sale at present". Por eso, "when the market clears, I will advice you". ${ }^{39}$

${ }^{39}$ MHS, Hooper Sturgis Papers, Ms-n 1435, caja 7. 
El estado del mercado estaba también relacionado con el estatus que adquiría un agente. Había dos problemas relacionados con el envío de información, los cuales iban más allá de la exactitud necesaria y la temporalidad de accionar del agente que la recibía. El tiempo que una lista de precios tardaba en llegar a su puerto de destino y en que los artículos eran remitidos, podía ser a su vez el tiempo suficiente para que los precios se derrumbasen y que se causasen pérdidas allí donde se habían ofrecido ganancias aseguradas. Es aquí donde se conseguía evaluar la competencia de un agente determinado, esto es, su capacidad de generar los retornos sobre precios que habían sido propuestos. Este desempeño podía ser hasta cierto punto evaluado (la capacidad del agente para generar ganancias) y no dependía de la manera como el grupo de comerciantes percibía a un agente, al generar relaciones asimétricas entre diferentes miembros que transaban entre sí. Había, sin embargo, que tomar precauciones con la información que circulaba, pues cartas de presentación de personas interesadas en entrar al juego eran en general acompañadas de listas de precios. Informar el estado del mercado, era entonces, colorear los precios con los calificativos adecuados para generar atracción sobre los agentes, previendo el comportamiento futuro de la demanda. Se trataba de un círculo cerrado, pues los agentes que conseguían tener éxito en calificar el mercado conseguían generar estatus, sin embargo, el informe del mercado por parte de un sujeto con gran estatus repercutía a su vez en las tendencias del mercado y de los otros agentes.

\section{CONCLUSIONES}

El análisis detallado de la correspondencia de varias casas comerciales estadunidenses y su giro de capital en el Caribe español, permite analizar con más detalle cómo funcionaba la selección y mantenimiento de las operaciones a larga distancia, así como la inmensa cantidad de agentes involucrados y sus respectivas tareas. Este trabajo ha analizado el funcionamiento del comercio a larga distancia desde una perspectiva de las instituciones mercantiles. Dos conclusiones provisorias pueden ser subrayadas. En primer lugar, aunque se ha descrito a los comerciantes estadunidenses fundamentalmente como agentes involucrados en la extracción de la plata y la inundación del mercado habanero con harina, esta imagen debe complementarse con otra más matizada que dé cuenta de la manera como estos negociantes generaron cierto impacto en el mercado cubano. Las cuentas de Girard apuntan hacia el hecho de que el promedio de mercancías cargadas alcanzaba un índice alto y que la preocupación no se restringía sólo a la extracción de plata. Al entregar consignaciones y colocar en 
competencia diferentes casas comerciales en La Habana, los americanos dinamizan el mercado generando impactos sobre la demanda y los precios de azúcar o la preferencia de los comerciantes locales por la consignación de mercancías o la especulación con productos agrícolas. Se trata de redes mucho más dinámicas que se estructuran y desestructuran con una celeridad sobre la que habría que dar cuenta con mayor precisión. A su vez, la dinámica del mercado hace mucho más compleja la toma de decisiones por parte de los agentes involucrados. Habría, sin duda, que prestar mayor atención a la manera como los agentes reaccionaron ante las condiciones de mercado. Por otro lado, y no menos importante, los estadunidenses surten la isla con los textiles necesarios para el tráfico de esclavos, conectando la isla con los mercados lejanos de Calcuta y Macao. En segundo lugar, el empleo de la consignación por parte de los estadunidenses estaba soportado en una competencia en el uso de consignatarios y al tiempo en el envío de sumas de capital que no parecen ser tan elevadas pero que debían tener una circulación bastante acelerada. Este último dato en verdad desempeñó un papel esencial: el mantenimiento de una red de circulación de barcos permitía que el ciclo de circulación de capital fuera bastante rápido. Dicho brevemente, poco capital a una alta tasa de circulación. Esta hipótesis necesita una muestra más amplia que contraponga diferentes tipos de casas comerciales con capitales diferentes, pues como se ha expuesto, el cargamento de Girard era mucho mayor que el de casas como Brown and Ives o Brian and Sturgis. Ahora bien, al ser propietarios de los barcos, estos comerciantes estaban obligados a velar por el cargamento de mercancías que generase flete o a conseguir flete para cubrir los gastos de los barcos. Este factor desempeña un papel fundamental en la toma de decisiones de los agentes involucrados en las operaciones mercantiles. Aunque las cartas muestran ampliamente una "retórica de la confianza", la verdad es que los agentes eran monitoreados o puestos bajo el estrés de una alta competición con el fin de obtener mejores resultados. Al elegir los agentes, el estatus (diferente de la reputación) era uno de los factores calculados en mayor detalle.

\section{LISTA DE REFERENCIAS}

Amore, M. D. (2016). Social capital and family control. Explorations in Economic History. DOI: 10.1016/j.eeh.2016.06.001

Amores, J. (2000). Cuba en la época de Ezpeleta (1785-1790). Pamplona: Universidad de Navarra.

Aslanian, S. (2011). From the Indian ocean to the Mediterranean: The global trade networks of Armenian merchants from New Julfa. Berkeley: California University Press. 
Barbier, J. y Kuethe, A. (eds.) (1984). The North American role in the spanish imperial economy, 1760-1819. Manchester: Manchester University Press.

Beckert S. (2014). Empire of cotton: A global history. Nueva York: Alfred A. Knopf.

BOHORQuez, J. (2016). Globalizar el sur. La emergencia de ciudades globales y la economía política de los imperios portugués y español: Río de Janeiro y La Habana durante la era de las revoluciones (Tesis doctoral). European University Institute, Italia.

BötTcher, N. (2000). Juan de Miralles: un comerciante cubano en la guerra de independencia norteamericana. Anuario de Estudios Americanos, 57(1), 171-194. DOI: 10.3989/aeamer.2000.v57.i1.263

BötTcher, N. (2011). Comerciantes británicos y el comercio interior de Cuba, 17621808. En N. Böttcher, B. Hausberger y A. Ibarra (coords.), Redes y negocios globales en el mundo ibérico, siglos XVI-XVIII (pp. 207-238). Madrid: Iberoamericana.

Böttcher, N., Hausberger, B. e IbArRA, A. (coords.) (2011). Redes y negocios globales en el mundo ibérico, siglos XVI-XVIII. Madrid: Iberoamericana.

Coughtry, J. (1981). The notorious triangle. Rhode Island and the African slave-trade 17001807. Filadelfia: Temple University Press.

Cuenca-Esteban, J. (1984). Trends and cycles in U. S. trade with Spain and the spanish empire, 1790-1819. The Journal of Economic History, 44(2), 521-543. DOI: 10.1017/ S0022050700032113

Cuenca-Esteban, J. (2014). British "gosth" exports, American middlemen, and the trade to Spanish America, 1790-1819. A speculative reconstruction. William and Mary Quarterly, 71(1), 63-98. DOI: 10.5309/willmaryquar.71.1.0063

Debien, G. (1953). Les colonos de Saint-Domingue réfugiés a Cuba (1793-1815). Revista de Indias, 13-14(55-56), 559-605, 11-36.

Doosselaere, Q. (2006). Commercial agreements and social dynamics in medieval Genoa. Cambridge: Cambridge University Press.

Fernández, N. (2000). Las balanzas del comercio exterior de La Habana de 1803 a 1807. Bilbao: Universidad del País Vasco.

FERnández, N. (2002). Comercio exterior y fiscalidad: Cuba, 1794-1860. Bilbao: Universidad del País Vasco.

Ferreira, R. (2001). Dinâmica do comércio intracolonial: Geribitas, panos asiáticos e guerra no tráfico angolano de escravos (século XVIII). En J. Fragoso y M. F. Gouvêa, O Antigo Regime nos trópicos: a dinâmica imperial portuguesa (séculos XVI-XVIII) (pp. 340-378). Río de Janeiro: Civilização Brasileira.

GambetTA, D. (1988). Trust: Making and breaking cooperative relations. Oxford: Blackwell.

Gelderblom, O. (2013). Cities of commerce. The institutional foundations of international trade in the Low Countries, 1250-1650. Princeton: Princeton University Press.

Goldberg, J. (2012). Trade and institutions in the medieval Mediterranean: The Geniza merchants and their business world. Cambridge: Cambridge University Press.

GonÇALVES, D. (2008). Le planteur et le roi. L'aristrocratie havanaise et la couronne d'Espagne (1763-1838). Madrid: Casa de Velázquez. 
GonZÁlez-Ripoll, M. (1999). Cuba, la isla de los ensayos: cultura y sociedad, 1790-1815. Madrid: Consejo Superior de Investigaciones Científicas.

Granovetter, M. (1978). The strenght of weak ties. American Journal of Sociology, 78(6), 1360-1380. DOI: $10.1086 / 225469$

GREIF, A. (2000). The fundamental problem of exchange: A research agenda in historical institutional analysis. European Review of Economic History, 4(3), 251-284. DOI: $10.1017 / \mathrm{S} 1361491600000071$

GREIF, A. (2006). Institutions and the path to the modern economic. Lessons from the medieval trade. Cambridge: Cambridge University Press.

Greif, A. (2012). Maghribi traders: A reappraisel? The Economic History Review, 65(2), 445-469. DOI: 10.1111/j.1468-0289.2012.00645.x

Guinnane, T. (2005). Trust: A concept too many. Jahrbuch für Wirtschaftsgeschichte, 46(1), 77-92. DOI: 10.1524/jbwg.2005.46.1.77

HagGertTy, S. (2009). Risk and risk management in the Liverpool slave trade. Business History, 51(6), 817-834. DOI: 10.1080/00076790903266844

Haggerty, S. (2012). Merely for money?: Business culture in the British Atlantic, 17501815. Liverpool: Liverpool University Press.

HANCOCK, D. (1995). Citizens of the world. London merchants and the integration of the British Atlantic. Cambridge: Cambridge University Press.

IrIGOIN, A. (2009). The end of the silver era: Global consequences of the breakdown of the spanish silver peso standard in China and the United States, 1780s-1850s. Journal of World History, 20(2), 207-244 A. DOI: 10.1353/jwh.0.0053

Johnson, S. (2001). The social transformation of eighteenth century Cuba. Gainesville: University Florida Press.

Jurisprudencia Civil (1861). Colección completa de las sentencias dictadas por el tribunal supremo de Justicia en recursos de nulidad, casación e injusticia notoria y en materia de competencias, desde la organización de aquellos de 1838 hasta el día. Madrid: Revista Imprenta de la Legislación.

KNigHT, W. (1977). Origins of the wealth and the sugar revolution in Cuba, 1750-1850. Hispanic American Historical Review, 57(2), 231-253.

Kuethe, A. J. (1991). Havana in the Eighteenth Century. En F. Knight y P. K. Liss (eds.), Atlantic port cities. Economy, culture, and society in the Atlantic world, 1560-1850 (pp. 13-39). Knoxville: University of Tennessee Press.

Kuethe, A. J. e IngLis, G. D. (1985). Absolutism and enlightened reform: Charles III, the establishment of the Alcabala and commercial reorganization in Cuba. Past and Present, 109(1), 118-143. DOI: 10.1093/past/109.1.118

LAmikiz, X. (2010). Trade and trust in the eighteenth-century Atlantic world: Spanish merchants and their overseas networks. Londres: Royal Historical Society.

LAMIKIZ, X. (2011). Transatlantic networks and merchant guild rivalry in colonial trade with Peru, 1729-1780: A new interpretation. Hispanic American Historical Review, 91(2), 299-331. DOI: 10.1215/00182168-1165226 
LEWIS, J. (1984). Anglo-American entrepreneurs in Havana: The background and significance of the expulsion of 1784-1785. En J. BARBIER y A. J. KuETHE (eds.), The North American role in the Spanish imperial economy, 1776-1826 (pp. 112-133). Manchester: Manchester University Press.

Lopez, R. e Irving, R. (1967). Medieval trade in the Mediterranean world: Illustrative documents. Nueva York: Columbia University Press.

Machado, P. (2014). An ocean of trade: South Asian merchants, Africa and the Indian Ocean, c 1750-1850. Cambridge: Cambridge University Press.

Marichal, C. y Souto, M. (1994). Silver and Situados: New Spain and the financing of the Spanish empire in the Caribbean in the eighteenth century. The Hispanic American Historical Review, 74(4), 587-613. Recuperado de http://www.jstor.org/ stable/2517493

Moreno, M. (1964). El ingenio. El complejo económico social cubano del azúcar. Tomo I: 1760-1860. La Habana: Comisión Nacional Cubana de la UNESCO.

NASH, R. C. (2005). The organization of trade and finance in the British Atlantic economy, 1600-1830. En P. Coclanis (org.), The Atlantic economy during the seventeenth and eighteenth centuries. Organization, operation, practices and personnel (pp. 95-112). Columbia: University South Caroline.

Pearce, A. (2007). British trade with Spanish America, 1763-1808. Liverpool: Liverpool University Press.

Piqueras, J. (2008). La siempre fiel isla de Cuba, o la lealtad interesada. Historia Mexicana, 58(1), 427-486.

PRICE, J. (1989). What did merchants do? Reflections on British overseas trade, 16601790. Journal of Economic History, 49(2), 267-284. DOI: 10.1017/S0022050700007920

Riello, G. y Parthasarathi, P. (eds.) (2011). The spinning world: A global history of cotton textiles, 1200-1850. Oxford: Oxford University Press.

Riello, G. y Tirthankar, R. (eds.) (2009). How India clothed the world: The world of South Asian textiles, 1500-1850. Leiden: Brill.

SAGRA, R. (1831). Historia económico-política y estadística de la isla de Cuba o de sus progresos en la población, la agricultura, el comercio y las rentas. La Habana: Imprenta de la Viuda de Arazoza y Soler.

SalvucCI, L. (1985). Development and decline: The port of Philadelphia and Spanish imperial markets, 1783-1823 (Tesis doctoral). Princeton University, Estados Unidos.

SAlvUCCI, L. (1991). Supply, demand, and the making of a market: Philadelphia and Havana at the beginning of the nineteenth century. En F. W. KNIGHG y P. K. LISS (eds.), Atlantic port cities: Economy, culture, and society in the Atlantic world, 1650-1850 (pp. 40-57). Knoxville: University of Tennessee Press.

SAlvuCCI, L. (2005). Atlantic intersections: Early American commerce and the rise of the Spanish West Indies. Business History Review, 79(4), 781-809. DOI: $10.2307 / 25097114$

Socolow, S. (1978). The merchants of vice-regal Buenos Aires: Family and commerce. Nueva York: Cambridge University Press. 
Stein, B. y Stein, S. (2009). Edge of crisis. War and trade in the Spanish Atlantic. Baltimore: Johns Hopkins.

Strum, D. (2014). O comércio do açúcar. Brasil, Portugal e Paises Baixos (1595-1630). Río de Janeiro: Versal Editores.

TORnero, P. (1996). Crecimiento económico y transformaciones sociales. Esclavos, hacendados y comerciantes en la cuba colonial (1760-1840). Madrid: Ministerio de Trabajo y Seguridad Social.

Trivellato, F. (2009). The familiarity of strangers: The Sephardic diaspora, Livorno, and cross-cultural trade in the early modern period. New Haven: Yale University Press.

VAlle, G. DEL (2012). Finanzas piadosas y redes de negocios. Los mercaderes de la ciudad de México. México: Instituto de Investigaciones Dr. José María Luis Mora.

VAnneste, T. (2012). Global trade and commercial networks: Eighteenth-century diamond merchants. Londres: Pickering and Chatto.

VÁzQUez, S. (2008). Tan difíciles tiempos para Cuba. El gobierno del marqués de Someruelos (1799-1812). Sevilla: Universidad de Sevilla.

Williamson, O. (1993). Calculativeness, trust, and economic organization. The Journal of Law and Economics, 36(1, parte 2), 453-486. DOI: 10.1086/467284

Zahedien, N. (2010). The capital and the colonies. London and the Atlantic economy 16601700. Cambridge: Cambridge University Press.

\section{Archivos}

AGI Archivo General de Indias, Sevilla, España.

JCB John Carter Brown Library, Providence, Estados Unidos.

MHS Massachusetts Historical Society, Boston, Estados Unidos.

PHS Philosophical Historical Society, Filadelfia, Estados Unidos. 